Biol. Neonate 1985;48:181-183

\title{
Contents, Vol. 48, No. 4, 1985
}

\section{Hormonal and Metabolic Changes in the Perinatal Period}

Mayor, F.; Cuezva, J.M 185

Decreased Uterine Blood Flow in the Diabetic Pregnant Rat Does Not Modify the Augmented Glucose Transfer to the Fetus

Palacín, M.; Lasunción, M.A.; Martin, A.; Herrera, E

Insulin and Glucagon during the Perinatal Period: Secretion and Metabolic Effects on the Liver

Ktorza, A.; Bihoreau, M.-T.; Nurjhan, N.; Picon, L.; Girard, J 204

Effect of Glucose and Insulin Administration on Hepatic Adenylate Energy Charge and the Cytosolic Redox State in the Neonates of Normal and Insulin-Treated Diabetic Rats

Cuezva, J.M.; Patel, M.S 221

Influence of Hormones and Undernutrition on Brain Development in Newborn Rats

Pascual-Leone, A.M.; Escrivá, F.; Alvarez, C; Goya, L.; Rodriguez, C 228

The Role of Lactate as an Energy Substrate for the Brain during the Early Neonatal

Period

Medina, J.M 237

Contribution of Brown Fat to the Neonatal Thermogenesis

Benito, M 245

Gamma-Glutamyl-Amino Acids as Signals for the Hormonal Regulation of Amino Acid Uptake by the Mammary Gland of the Lactating Rat

Vina, J.R.; Puertes, I.R.; Montoro, J.B.; Saez, G.T.; Vina, J 250 